\title{
OCENA EFEKTYWNOŚCI NOWEJ GENERACJI BETONÓW OSŁONOWYCH PRZED PROMIENIOWANIEM JONIZUJĄCYM W OPARCIU O POMIARY WE WZORCOWYCH POLACH PROMIENIOWANIA
}

\begin{abstract}
W artykule przedstawiono wyniki pomiarów właściwości osłonowych przed promieniowaniem jonizującym (gamma i neutronowym) betonów zwykłych i ciężkich, które poddano dodatkowej modyfikacji materiałowej przy użyciu wyselekcjonowanych dodatków. Pomiary wykonywano we wzorcowych polach promieniowania gamma (źródło Cs-137 i Co60) oraz promieniowania neutronowego (źródło Pu-Be). Na podstawie wyznaczonych wartości grubości HVL i TVL potwierdzono skuteczność betonów ciężkich jako osłon przed promieniowaniem gamma oraz dokonano oceny modyfikacji materiałowych w celu poprawy osłonności. Efektywnymi dodatkami zarówno wobec promieniowania gamma jak i neutronowego okazał się zarówno tlenek gadolinu jak i dyspersja polimerowa.
\end{abstract}

Słowa kluczowe: HVL, TVL beton ciężki, tlenek gadolinu, polimer

\section{Beton osłonowy nowej generacji}

Beton to podstawowy materiał, który obok funkcji konstrukcyjnej w obiekcie budowlanym może pełnić równocześnie funkcję osłony biologicznej przed promieniowaniem jonizującym. Historycznie, elementy $\mathrm{z}$ betonu osłonowego mają znaczne grubości. Nie wymagało się wtedy, aby beton miał bardzo wysokie parametry wytrzymałościowe, natomiast istota była ich trwałość. Obecnie jednak mamy do czynienia z betonami nowej generacji, które korzystają z najnowszych osiągnięć w technologii betonu. Przede wszystkim są to betony wysokowarto-

\footnotetext{
1 Autor do korespondencji/corresponding author: Tomasz Piotrowski, Politechnika Warszawska, Wydział Inżynierii Lądowej, Al. Armii Ludowej 16, 00-637 Warszawa, +48 222346480 , t.piotrowski@il.pw.edu.pl

${ }^{2}$ Michał A. Gryziński, Narodowe Centrum Badań Jądrowych, ul. Andrzeja Sołtana 7, 05-400 Otwock, +48 2227311 57, michal.gryzinski@ncbj.gov.pl
} 
ściowe BWW tj. betony cementowe o niskim współczynniku $\mathrm{w} / \mathrm{c}=0,25 \div 0,35$ na kruszywach naturalnych z odpowiednimi dodatkami i domieszkami. Współczesne betony nowej generacji to jednak nie tylko tak zdefiniowane BWW, ale także betony określane mianem betonów specjalnych, w tym m.in. beton samozagęszczalny, zbrojony włóknami, natryskowy, żaroodporny, podwodny, posadzkowy oraz beton do konstrukcji masywnych, ale także właśnie beton osłonowy. Beton taki powinien się charakteryzować następującymi właściwościami:

- podwyższone parametry osłonowe przed promieniowaniem jonizującym,

- trwałość - betonu stosowany w elektrowniach jądrowych powinien mieć trwałość na min. 80 lat (tyle wynosi czas życia zbiornika reaktora w obecnie budowanych reaktorach generacji III+),

- odpowiednio wysokie podstawowe parametry wytrzymałościowe i użytkowe.

Beton taki należy zatem określać betonem wysokowartościowym, chociażby z uwagi na jego zwiększoną trwałość. Również inne wymagania dla betonu zawarte w RCC-CW [4] znacznie wykraczają ponad standardowe wymagania dla betonu opisane w PN-EN 206, które przewidują jedynie 50 lat trwałości [2].

\subsection{Rodzaje promieniowania jonizującego}

Promieniowanie jonizujące jest to promieniowanie, które wywołuje tzw. jonizację, czyli wybicie elektronu bądź cząsteczki z materii i spowodowanie powstania w niej ładunków elektrycznych. Granica pomiędzy promieniowaniem jonizującym a niejonizującym przyjęta została na granicy widma światła widzialnego i ultrafioletu. Wyróżnia się cztery rodzaje promieniowania jonizującego: alfa, beta, elektromagnetyczne (rentgenowskie i gamma) oraz neutronowe. Promieniowanie jonizujące może uszkadzać żywe komórki, powodując negatywne skutki dla zdrowia na skutek przekazana energii jednostce masy materii (jednostka $1 \mathrm{~Gy}=\mathrm{J} / \mathrm{kg}$ ). $\mathrm{Z}$ tego powodu konieczne jest stosowanie osłon przed tym promieniowaniem. Miarą stopnia narażenia człowieka na działanie promieniowania jonizującego jest dawka skuteczna $E_{H}$ liczona jako suma równoważników dawki we wszystkich narządach i tkankach z uwzględnieniem ich współczynników wagowych zgodnie ze wzorem (1);

$$
E_{H}=\sum_{T} \omega_{T} H_{T}=\sum_{T} \omega_{T} \sum_{R} \omega_{R} D_{T, R} \quad[S v]
$$

gdzie: $H_{T}$ - równoważnik dawki pochłoniętej dla tkanki $T, \omega_{T}$ - czynnik wagowy tkanki (narządu) $T, \omega_{R}$ - czynnik wagowy promieniowania $R, D_{T, R}$ - średnia dawka pochłonięta promieniowania $R$ przez tkankę $T$.

Opisując osłabienie promieniowania najczęściej posługuje się pojęciem warstwy półchłonnej lub warstwy osłabienia połówkowego (Half-Value Layer HVL); jest to grubość danego materiału, która osłabia do połowy pierwotne natężenie przechodzącego promieniowania. Analogicznie warstwa osłabienia dziesięciokrotnego (Tenth-Value Layer TVL); jest to grubość danego materiału, która osłabia dziesięciokrotnie pierwotne natężenie przechodzącego promieniowania. 


\subsection{Właściwości osłonowe betonu}

Dotychczasowe badania wskazują, iż optymalny skład betonu osłonowego przed promieniowaniem gamma jest inny niż betonu osłonowego przed promieniowaniem neutronowym [3-4]. Wynika to ze specyficznego oddziaływania neutronów $\mathrm{z}$ materią, $\mathrm{w}$ zależności od ich energii kinetycznej i tzw. przekrojów czynnych na różne reakcje $\mathrm{z}$ atomami wchodzącymi $\mathrm{w}$ skład betonu. Ma to szczególne znaczenie w przypadku, gdy mamy do czynienia ze źródłami promieniowania emitującymi neutrony o dużych energiach (tzw. neutrony prędkie). Dziej się tak w tzw. reaktorach IV generacji oraz jednej z najnowszych metod teleradioterapii - terapii szybkimi neutronami (FNT - Fast Neutron Therapy). Ponieważ przekrój czynny na absorpcję neutronów prędkich jest mały, to przegrodę należy wykonać tak, aby atomy, z których się składa, najpierw spowodowały spadek energii neutronów w procesach rozpraszania sprężystego i niesprężystego, a następnie miała miejsce absorpcja neutronów powolnych przez odpowiednie atomy pierwiastków wchodzących w skład betonu.

\section{Pomiary we wzorcowych polach promieniowania}

Przedmiotem badań były płyty betonowe o wymiarach 400x400x50 mm wykonane $\mathrm{z}$ różnych mieszanek betonowych. Były to betony referencyjne wykonane przy użyciu CEM III 42,5R i wskaźniku w/c=0,4: beton zwykły na kruszywie granitowym $(\mathrm{Z})$ oraz beton ciężki magnetytowy $(\mathrm{M})$. Dodatkowy konano beton ciężki magnetytowy z użyciem CEM I 42,5 R. Betony referencyjne następnie zmodyfikowano dodając zastępujące modyfikatory:

- tlenek gadolinu $\left(\mathrm{Gd}_{2} \mathrm{O}_{3}\right)$ w ilości 0,5 i 1,0\% masy cementu (ZG 0.5 i ZG 1.0 oraz MG 0.5 i MG 1.0),

- makrowłókna polimerowe (MF1) lub mikrowłókna polipropylenowe (MF2) oraz ich połączenie $(\mathrm{MF} 1+2)$,

- dyspersja akrylową (MPCC1) lub dyspersją epoksydowa (MPCC2),

- nieorganiczny związek chemiczny z grupy wodorków zawierający bor, który jest stosowany jako magazyn wodoru w ogniwach wodorowych (H2).

Pomiary przeprowadzono wg indywidualnie opracowanego programu [1] na specjalnie przygotowanym stanowisku, które składało się z konstrukcji stalowej, z poziomymi płytami z płyty pilśniowej zapewniającymi bezpieczne pozycjonowanie wertykalne nawet do 12 płyt o grubości $50 \mathrm{~mm}$ umieszczonych prostopadle do mechanizmu pozycjonowania źródła promieniowania. Ze względu na geometrię pomieszczenia badawczego i analizy oparte na obliczeniach Monte Carlo optymalną wysokością pozycjonowania źródła nad powierzchnią podłogi jest $1000 \mathrm{~mm}$. Źródło promieniowania na czas trwania pomiarów przenoszono do nieużywanego slotu umieszczonego w pozycji bezpiecznej pod powierzchnią podłogi. Na czas pomiarów w sposób zdalny źródło jest wysuwane za pomocą wciągnika elektrycznego. Różnice w pozycjonowaniu źródła, które 
w osi prostopadłej do powierzchni podłogi wynosi $\pm 30 \mathrm{~mm}$ jest z punktu widzenia pomiarowego pomijalne. Wynika to z dosyć dużej powierzchni próbki która wynosi $1600 \mathrm{~cm}^{2}$ oraz faktu, iż źródło promieniuje w sposób izotropowy. Prace obejmowały także skonfigurowanie systemu pomiarowego, w skład którego wchodziły dwie rekombinacyjne komory jonizacyjne typu REM 2.8 oraz GW2 [4]. Decyzja o wyborze ww. komór jonizacyjnych wynikała z charakteru zastosowanego źródła promieniowania jonizującego, które w zasadzie jest źródłem promieniowania neutronowego jednak równolegle do niego występuje składowa gamma, której obecność zaburza pomiar i wprowadza błąd. Komora jonizacyjna typu REM 2.8 jest komorą równoważną tkance, a więc jest detektorem czułym zarówno na składową neutronową jak i na składową gamma. Komora typu GW2 jest komorą bezwodorową, co oznacza, że jej czułość neutronowa jest pomijalna względem czułości na promieniowanie gamma. Pozwala to na określenie składowych oraz przedstawienie kolejnych wyników uwzględniających wpływ składowej gamma.

\subsection{Promieniowanie gamma}

Zarówno dla źródła Cs-137 jak i Co-60 wyznaczono czterokrotnie wartość HVL i trzykrotnie wartość TVL. Każda kolejna wartość oznacza grubość warstwy chłonnej po osłabieniu promieniowania przez poprzednią warstwę. Stwierdzono, że różnice miedzy kolejnymi wartościami wynoszą <10\%. W przypadku źródła Cs-137 zaobserwowano wzrost skuteczności osłony przy HVL i utrzymanie skuteczności przy TVL, natomiast dla źródła Co-60 zarówno przy HVL jak i TVL stwierdzono spadek skuteczności osłon wraz z grubością (Rys.1).

Przeprowadzone pomiary potwierdziły znaną zależność właściwości osłonowych względem promieniowania gamma od gęstości - beton ciężki (M) uzyskał o 20-30\% niższe wartości HVL i TVL od betonu zwykłego (Z) (Rys.2). Analiza skuteczności dodatków wskazuje, że jedynie dla betonu ciężkiego gadolin polepsza właściwości osłonowe i zarówno HVL jak TVL maleje proporcjonalnie do jego zawartości osiągając 10\% spadek wartości HVL i TVL przy $1 \%$ $\mathrm{Gd}_{2} \mathrm{O}_{3}$. Zbrojenie rozproszone okazało się mniej skuteczne - dodatek włókien

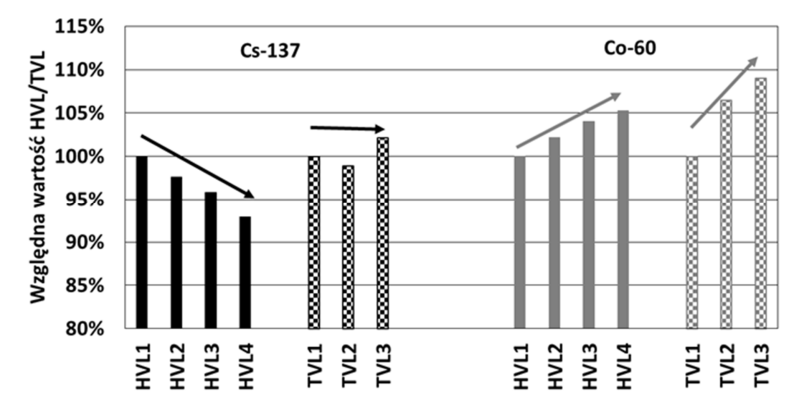

Rys. 1. Względne średnie wartości HVL i TVL względem źródeł gamma dla wszystkich próbek

Fig. 1. Relative mean values of HVL and TVL in gamma source for all the samples 
(zarówno polimerowych jak i polipropylenowych) powodował spadek HVL i TVL o ok. 6\%. Najbardziej skuteczny okazał się dodatek dyspersji polimerowej - spadek HVL i TVL nawet o 13\%. Niestety nie stwierdzono synergii addytywnej w działaniu dodatku gadolinu i polimeru - spadek HVL i TVL dla Cs-137 wyniósł $8 \%$ i dla Co-60 - 6\%. Dobry wynik uzyskano także dla betonu z dodatkiem $\mathrm{H} 2$.

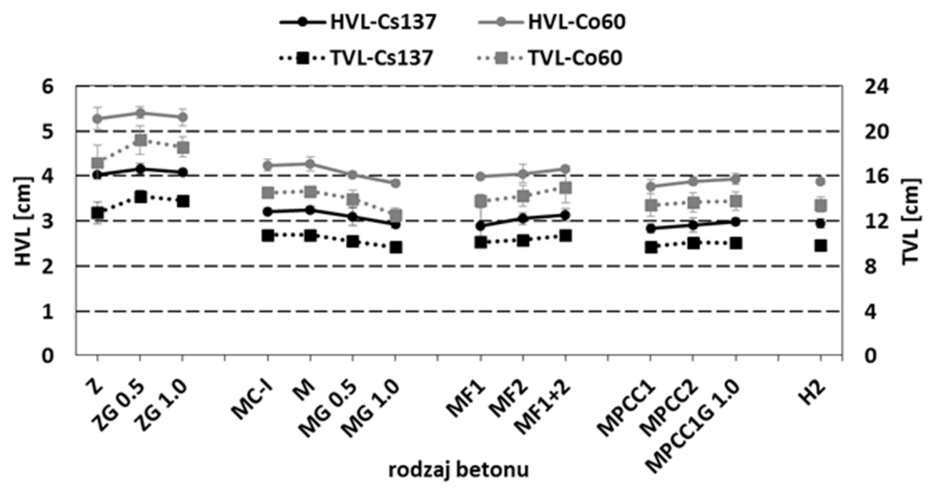

Rys. 2. Wartości średnie HVL i TVL dla źródeł gamma w zależności od rodzaju betonu

Fig. 2. Mean values of HVL and TVL for specific concretes measured in gamma radiation source

\subsection{Promieniowanie neutronowe}

Na wykresach przedstawiono wartości prądu jonizacji w zależności od grubości dla płyt betonowych poddanych badaniom (Rys 3-4). Wykresy podzielono w zależności od rodzaju wykorzystanego detektora oraz przyłożonego napięcia polaryzującego. Analiza wyników pozwala ocenić, że w przypadku detektora czułego zarówno na promieniowanie neutronowe jak i gamma - REM2-8, w przebadanych rodzajach betonu różnice w prądzie jonizacji są małe zarówno przy napięciu $60 \mathrm{~V}$ jak i 999V. Jednakże uzyskane różnice pozwoliły na określenie wartości współczynnika HVL i QVL (Quater Value Length) dla różnych rodzajów betonów (Rys.5) oraz na analizę wartości współczynnika jakości promieniowania $\mathrm{Q}_{\mathrm{n}}$ i udziału promieniowania gamma w dawce całkowitej (Rys.6). W przypadku komory nieczułej na promieniowanie neutronowe - GW2 widoczne jest wyraźne rozwarstwienie otrzymanych krzywych na dwie grupy (Rys.4). Do pierwszej z nich należą wszystkie betony zwykłe. Do drugiej grupy o lepszych właściwościach osłonowych wobec promieniowania gamma należą betony ciężkie niezależnie od modyfikacji materiałowej. Wyniki te są zgodne z przewidywaniami i wynikami pomiarów przy źródle promieniowania gamma Cs-137 i Co-60 (Rys.2). Dla próbki MF1+2 wyniki odbiegają od linii trendu najprawdopodobniej na skutek popełnionego błędu podczas pomiarów. 

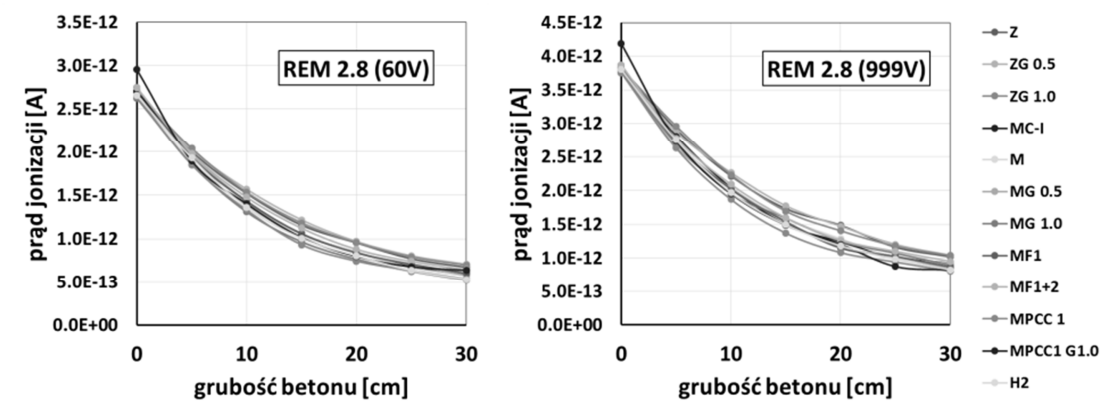

Rys. 3. Wartość prądu jonizacji w komorze REM 2.8 przy napięciu polaryzującym 60V i 999V

Fig. 3. Ionization current in REM 2.8 detector chamber in a polarized current $60 \mathrm{~V}$ and $999 \mathrm{~V}$

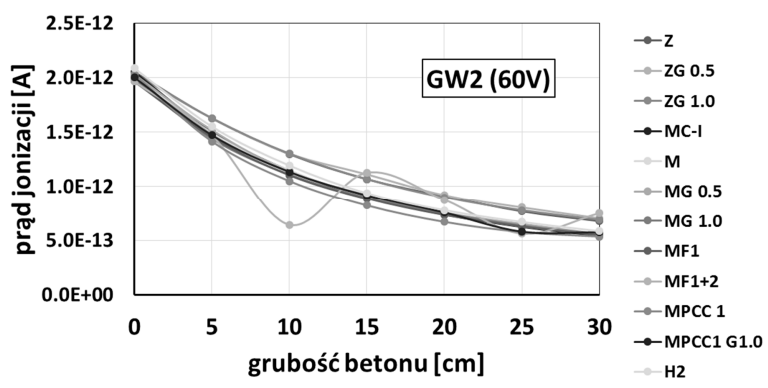

Rys. 4. Wartość prądu jonizacji w komorze GW2 przy przyłożonym napięciu polaryzującym 60V

Fig. 4. Ionization current value in $\mathrm{GW} 2$ detector chamber when a polarized current was $60 \mathrm{~V}$

W wyniku interpolacji funkcją wielomianową III stopnia określono wartości HVL i QVL dla źródła Pu-Be (Rys.3). Można zauważyć, że beton zwykły uzyskuje nieznacznie gorsze właściwości osłonowe niż beton ciężki (o ok. 10-12\% dla HVL). Bardzo dobre rezultaty daje modyfikacja materiałowa betonu ciężkiego zarówno przy użyciu gadolinu, włókien polimerowych jak i dodatku polimerowego (spadek HVL o kolejne 10\% w stosunku do betonu ciężkiego niemodyfikowanego, M). Najbardziej korzystne okazało się zastosowanie polimeru łącznie z tlenkiem gadolinu (spadek o 20\%) - można zatem stwierdzić, że w tym przypadku ujawnił się efekt synergistyczny modyfikacji. Należy pamiętać, że promieniowanie neutronowe jest promieniowaniem specyficznym ze względu na charakter oddziaływań dlatego należy przeprowadzić kolejne analizy uwzględniające zmiany widma promieniowania neutronowego na kolejnych warstwach materiału osłonowego. $\mathrm{Z}$ tego względu dla danych uzyskanych podczas pomiarów, wykreślono wartości wskaźnika jakości promieniowania $\mathrm{Q}_{\mathrm{n}}$ i udziału dawki od promieniowania gamma $w$ funkcji grubości materiału osłonowego (Rys.6). Gdy $\mathrm{Q}_{\mathrm{n}}$ rośnie zwiększa się udział promieniowania o wysokim liniowym współczynniku przenoszenia energii LET - neutrony są wyhamowywane w materiale przez co domino- 
wać zaczynają neutrony o niższych energiach (o wyższym współczynniku $Q_{n}$ tj. silniej oddziałujące). Uzyskane wartości obarczone są dość dużym błędem jednak można zauważyć rosnący trend wraz z grubością osłony. Zaobserwowano także wzrost udziału dawki od promieniowania gamma, co świadczy o tym, iż wraz z grubością podczas spowalniania i pochłaniania neutronów następuje emisja promieniowania wtórnego w postaci fotonów gamma.

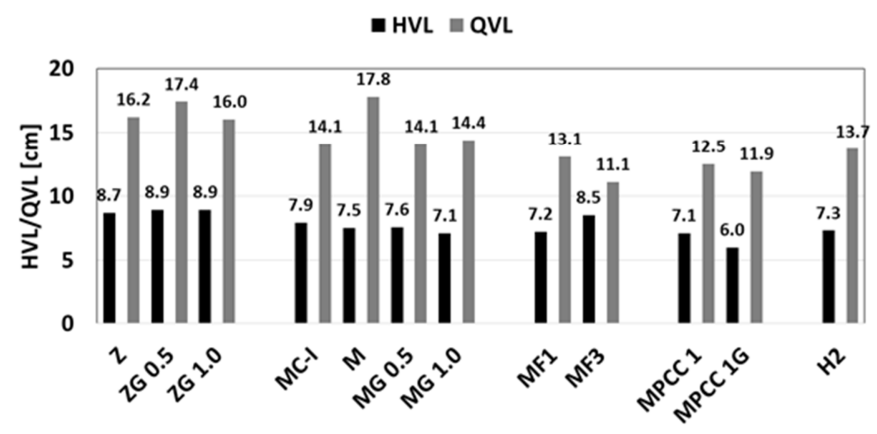

Rys. 5. Wartość HVL i QVL dla promieniowania neutronowego od źródła Pu-Be

Fig. 5. HVL and QVL values for specific concretes in Pu-Be neutron source
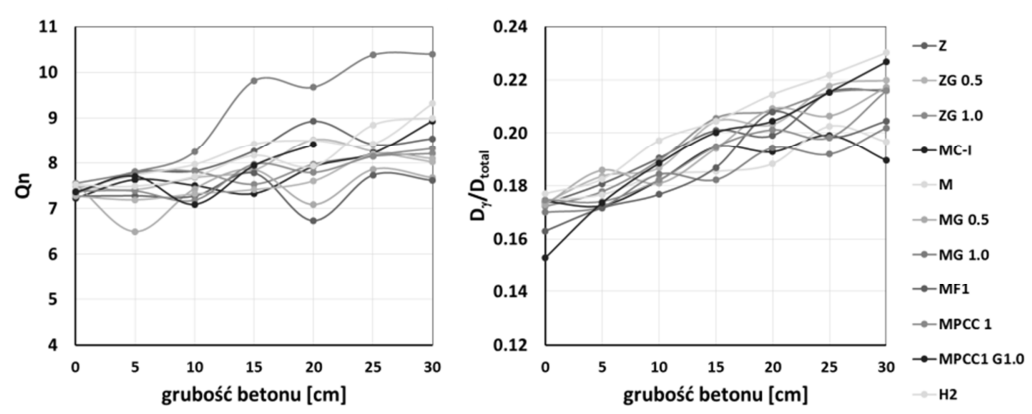

Rys. 6. Współczynnik jakości promieniowania $\mathrm{Q}_{\mathrm{n}} \mathrm{i}$ udział dawki promieniowania gamma w dawce całkowitej

Fig. 6. Radiation quality factor $\mathrm{Q}_{\mathrm{n}}$ and relative contribution of gamma radiation in total dose

\section{Wnioski}

Wyniki pomiarów uzyskane we wzorcowych polach promieniowania jonizującego (gamma oraz neutronowego) potwierdziły, że w przypadku promieniowania gamma zastosowanie betonu ciężkiego jest rozwiązaniem skutecznym poprawiającym osłonność o 20-30\%. Dla promieniowania neutronowego konieczne jest natomiast opracowanie nowej generacji betonów osłonowych zawierających składniki, których celem spowolnienie neutronów prędkich i/lub absorpcja neuronów termicznych. Należy przeprowadzić badania uwzględniają- 
ce zmiany udziału neutronów o różnych energiach na kolejnych warstwach materiału. Przeprowadzenie wnikliwej analizy danych i rozszerzenie zakresu prowadzonych pomiarów pozwoli na zoptymalizowanie betonu pod kątem osłonności wobec neutronów o różnych energiach. Najważniejszą ilościową i jakościową zmianą będą pomiary w polu promieniowania o większej gęstości strumienia neutronów.

Artykut powstat w ramach projektu LIDER/033/639/L-4/12/NCBR/2013

\title{
Literatura
}

[1] Domański S., Gryziński M. A., Maciak M., Murawski Ł., Tulik P., Tymińska K.: Experimental investigation on radiation shielding of high performance concrete for nuclear and radiotherapy facilities, Pol. J. Med. Phys. Eng., Vol. 22, No2, 2016.

[2] Piotrowski T.: Wymagania dotyczące betonu w elektrowni jądrowej typu EPR wg ETC-C a normalizacja w Polsce, Materiały Budowlane, 5 (489) 2013, 35-38.

[3] Piotrowski T.: Nowej generacji beton osłonowy przed promieniowaniem jonizującym, Materiały Budowlane 9 (517) 2015, 34-36.

[4] Piotrowski T., Tefelski D.B., Sokołowska J.J., Jaworska B.: NGS-Concrete-New Generation Shielding Concrete against Ionizing Radiation - the Potential Evaluation and Preliminary Investigation, Acta Phys Pol A, 128 (2B) 2015, B-9-13.

[5] RCC-CW: Design and construction rules for civil works in PWR nuclear islands, AFCEN 2015.

[6] Zielczyński, M., Golnik, N., Gryziński, M.A., Tulik, P.. The use of recombination chambers at radiation therapy facilities, Radiation Measurements 45, 2010 1472-1475.

\section{EFFECTIVENESS EVALUATION OF NEW GENERATION SHIELDING CONCRETE AGAINST IONIZING RADIATION BASED ON MEASUREMENTS IN STANDARD RADIATION FIELDS}

\begin{abstract}
S u m m a r y
The article presents the results of measurements of the properties of shielding against ionizing radiation (gamma and neutron) of ordinary and heavy-weight concrete, which were subjected to additional material modification with selected additives. Measurements were performed in the standard gamma radiation (source of Cs-137 and Co60) and neutron radiation (source $\mathrm{Pu}-\mathrm{Be}$ ) fields. Based on the determined values of HVL and TVL, the efficiency against gamma radiation of heavy-weight concrete was confirmed, and material modifications in order to improve neutron shielding was evaluated. Effective additions to both for the gamma and neutron radiation was gadolinium oxide and polymer dispersion as well.
\end{abstract}

Keywords: HVL, TVL, heavy-weight concrete, gadolinium oxide, polymer

Przestano do redakcji: 07.06.2016 $r$.

Przyjęto do druku: 30.06.2016 r.

DOI: $10.7862 / \mathrm{rb} .2016 .16$ 